\title{
Quantification of floating ephippia in lakes: a step to a better understanding of high dispersal propensity of freshwater plankters
}

\author{
Mirosław Ślusarczyk • Tomasz Grabowski • \\ Barbara Pietrzak
}

Received: 22 December 2014/Revised: 24 July 2015/Accepted: 10 August 2015/Published online: 3 September 2015

(C) The Author(s) 2015. This article is published with open access at Springerlink.com

\begin{abstract}
Planktonic cladocerans of the genus Daphnia are an example of organisms whose ability to disperse among aquatic habitats is limited to dispersal of dormant eggs, encapsulated in protective structures called ephippia. In the present study, we aimed to quantify the production of floating and sinking ephippia in lakes to test the hypothesis that, even if they eventually sink, most of them are first floating at the surface. In addition, we checked the egg content status of the ephippia. The results of this study revealed numbers of ephippia floating at lakes surface reaching thousands per square metre at the time of ephippia production, and constituting substantial share of that production. In studied shallow lowland lakes and in a deep mountain lake, most ephippia were first floating at the water surface, while in deep lowland lakes the proportion was reversed. Approximately half of ephippia that appeared initially at the water surface sank during the six-week sampling period. The egg content status did not differ between floating and sinking ephippia. High numbers of ephippial females staying in the surface layers at night in a mountain
\end{abstract}

Guest editors: Adam Petrusek \& Piet Spaak / Proceedings of the 10th International Symposium on Cladocera

M. Ślusarczyk $(\bowtie) \cdot$ T. Grabowski · B. Pietrzak Department of Hydrobiology, Faculty of Biology, University of Warsaw Biological and Chemical Research Centre, Żwirki i Wigury 101, 02-089 Warsaw, Poland e-mail: m.slusarczyk@uw.edu.pl lake, and a laboratory experiment with ephippial females indicated that ephippia are actively oviposited to the water surface by gravid females.

Keywords Dormant forms · Ephippia - Dispersal · Egg bank . Water surface

\section{Introduction}

While it is broadly acknowledged that plants use their dormant stages (e.g. seeds) for both temporal and spatial dispersal (Levin et al., 1984; Venable \& Brown, 1988; Baskin \& Baskin, 2001), animals are often considered to use dormant forms mostly for temporal dispersal. This is due to movement capabilities of animal active stages. Yet, the generalisation does not apply to all animals e.g. sessile ones or those inhabiting isolated sites, like parasites or animals in island habitats. In the present study, we investigate the prevalence of a mechanism that might facilitate spatial dispersal of diapausing forms of planktonic cladocerans of the genus Daphnia inhabiting island-like freshwater habitats.

Spatial dispersal is recognised to play a fundamental role in ecology of many plant and animal species (Clobert, et al., 2001; Silvertown \& Charlesworth, 2001; Cote et al., 2013), and dispersal capacity is expected to be under particularly strong selection pressure in isolated habitats, such as fresh waters 
(Kappes et al., 2014). Dispersing individuals display various traits increasing their dispersal capacity. This applies to both active and passive dispersers. The latter include parts of plants and both plant and animal resting stages, such as seeds or diapausing eggs, and need external facilitators to disperse.

For aquatic plants, hydrochory, water-mediated spread of seeds, plays an important role in their dispersal (Hopfensperger \& Baldwin, 2009; Pollux et al., 2009). Plant propagules float thanks to positive buoyancy or surface tension, and hence hydrochory is facilitated by traits increasing buoyancy and floating ability (Kappes et al., 2014; van Leeuwen et al., 2014). Indeed, seed floatability serves as proxy for their dispersal capacity (Kappes et al., 2014; van Leeuwen et al., 2014). For freshwater invertebrates unable to move actively between water bodies, having a dormant stage has often been considered an adaptation for dispersal in itself, and such stages dominantly contribute to passive dispersal of these organisms (Panov et al., 2004; Panov \& Cáceres, 2007). Also their floatability has been linked with dispersal capacity, e.g. floatoblasts and sessoblasts of bryozoans (Karlson, 1992), and floaters and sinkers of anostracans (Pinceel et al., 2013).

Likewise, cladoceran diapausing embryos enclosed in ephippia, often called "ephippial or resting eggs," not only rest, but also allow for a dispersal phase (Maguire, 1963; Bilton et al., 2001; Pietrzak \& Ślusarczyk, 2006). In fact, their functional similarity to seeds and the same dispersal mechanisms at work have been repeatedly noted (e.g. Figuerola \& Green, 2002; Altermatt \& Ebert, 2008). The eggs encapsulated inside ephippium show high thermal, desiccation, and digestion resistance (reviewed in Radzikowski, 2013), and the structure of ephippium itself makes it both an efficient protective and an adherent floating vessel. The outermost cuticular layer of the flattened ephippial case is densely spotted with microrecesses (Schultz, 1977; Du \& Li, 1990; Juračka et al. 2010). These physical, chemical, and morphological properties result in a highly hydrophobic structure. Ephippium is thus easily caught at the water-air phase boundary upon contact with water surface, despite its initial negative buoyancy (Ślusarczyk \& Pietrzak, 2008). It may get positive buoyancy if atmospheric air becomes absorbed by ephippial case or ephippium dries out. Floatability and adherence to objects are further enhanced by structures like dorsal spines (Hiruta \& Tochinai, 2014). Ephippia attachment to waterfowl has been long anticipated
(Havel et al., 2000), and shown both directly (Simonis \& Ellis, 2014) and indirectly through population genetics evidence for cladoceran dispersal mediated by waterfowl (Figuerola et al., 2005). The high floating ability of the ephippium can be expected to facilitate dispersal by animate (amphibious animals) and inanimate (wind, waterways) vectors, which prevail at the water surface.

Production of ephippia, and of floating ephippia above all, is thus the production of migrants. While the ephippia production of some Daphnia species has been quantified in lakes and ponds (e.g. Altermatt \& Ebert, 2008), their direct fate, i.e. sinking versus floating, has never been studied in natural habitats. Indeed, at the time of sexual reproduction, when dormant eggs are produced, large quantities of ephippia are found floating on lake water surface or at the lake shore (Jankowski \& Straile, 2003; Kerfoot et al., 2004) (Fig. 1). The reports, though, are mostly anecdotal, and to the best of our knowledge the phenomenon has not been quantified in the field.

Our former study reported common occurrence of floating ephippia in lowland lakes in a season of their mass production (Ślusarczyk \& Pietrzak, 2008). Moreover, we determined the way ephippia appear at the water surface: under laboratory conditions, all ephippia found at the water surface were actively deposited there by mothers (Ślusarczyk \& Pietrzak, 2008). All Daphnia species groups, i.e. D. magna, D. pulex, and D. longispina, tested there exhibited this surface oviposition behaviour despite an imposed threat (high intensity of UV radiation at the water surface) associated with it. Those experiments, carefully designed to test also for ephippia initial buoyancy, showed that without previous contact with the surface, all newly formed ephippia sink to the bottom. Finally, we found that different species differed in proportion of ephippia deposited at the water surface, with the lowest values reported in D. magna and the highest in the D. longispina group (Ślusarczyk \& Pietrzak, 2008). As the prevalence and mechanism behind ephippia floating on the surface was uncovered under artificial laboratory conditions, we now aim to evaluate occurrence of this phenomenon in natural habitats.

In the present study, we (1) aim to quantify the production of floating and sinking ephippia in lakes. Our hypothesis goes in line with the previous laboratory findings: majority of Daphnia ephippia produced in lakes first get to the surface, even though most of 

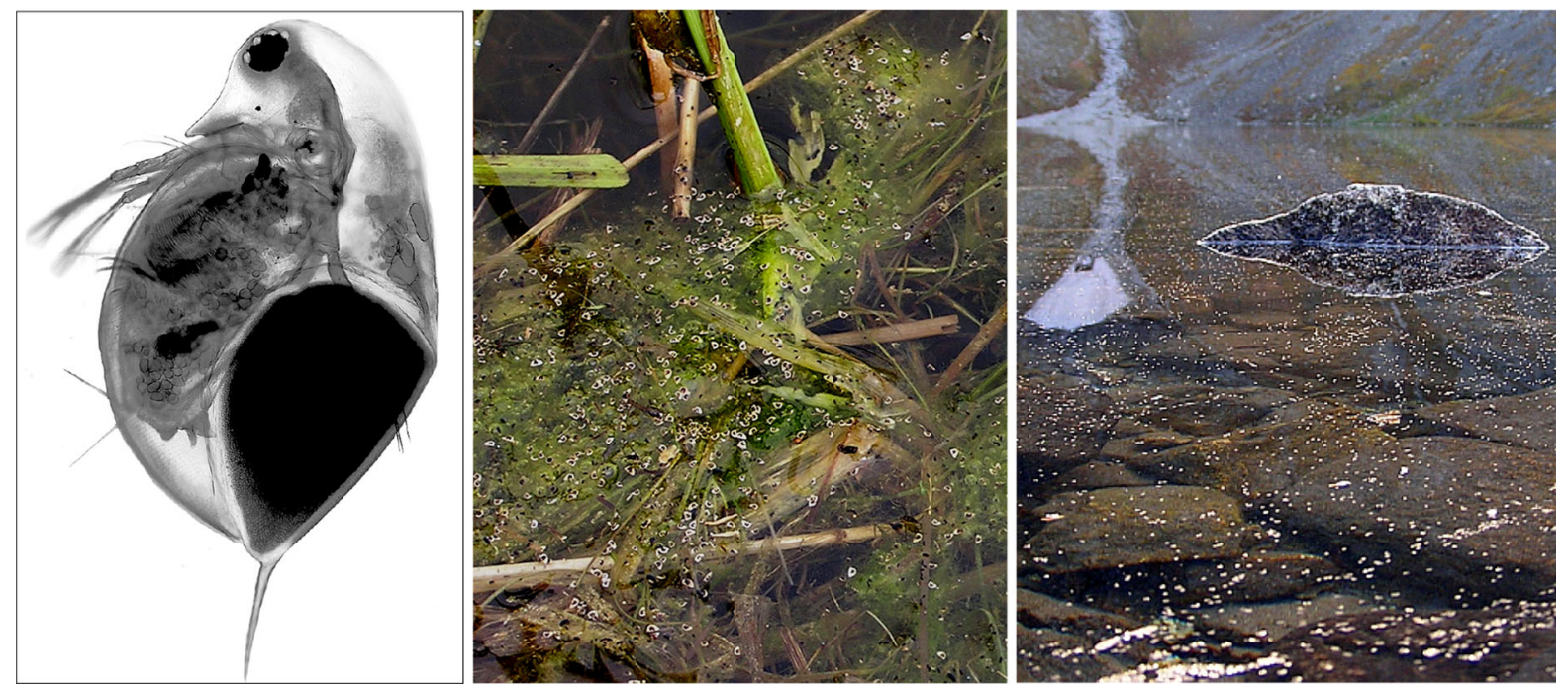

Fig. 1 Image of ephippial female of Daphnia (left), floating ephippia of Daphnia blown to the littoral vegetation in a shallow lake (middle), and high densities of ephippia of Daphnia floating on the surface of a mountain lake (right)

them may finally reach the bottom. As we consider this to be an adaptive life history trait rather than an accidental phenomenon (e.g. resulting from higher floatability of empty ephippial shells), we (2) compare the proportion of full, intact ephippia between floating and sinking ephippia, assuming that these do not differ. We also (3) look for indirect evidence of the surface oviposition behaviour taking place in natural habitats and anticipate different vertical distribution patterns in non-ephippial and ephippium-carrying females. As such oviposition behaviour of the females would incur risks associated with visual predation or UV radiation, we expect females to deposit ephippia at the surface at night if they do. We thus predict to find in the subsurface layers at night proportionately more ephippium-carrying than non-ephippial females. In the results, we show the relative abundances of ephippia floating at the surface and sinking to the bottom, their egg content status, and indications of their surface deposition at night by females.

\section{Methods}

Quantification of floating ephippia production

The study encompassed eight deep ( $>39 \mathrm{~m})$ and shallow $(<15 \mathrm{~m})$ lowland lakes inhabited by fish, and one deep fish-free alpine lake (Table 1). Ephippia of the dominant cladoceran species were considered, i.e. Daphnia of the longispina group in the lowland lakes and Daphnia of the pulex group in the mountain lake. Note that both shallow and deep lowland lakes are inhabited by Daphnia of the longispina group, yet the specific taxon composition may differ between lakes. The study was conducted at times of ephippia production in the respective lakes: during 6 weeks in August-September (2005) in the mountain lake (Slusarczyk, 2009), and during 6 weeks from early October to mid-November (2006) in the lowland lakes (Surga, 2007). Very shallow ponds and lakes were excluded from our study in order to eliminate the risk of sample contamination with resuspended ephippia, which is more likely in polymictic lakes.

We estimated the proportions of ephippia that were initially produced as floating or sinking, as well as the proportions of floating ephippia that sank during the field study. We applied a set of seston traps of three types of original construction, different from ones typically used so far. They have relatively large openings and compact transport size (Fig. 2). Two sets of these traps were placed in each studied lake. All locations were offshore and at spots of relatively gentle bottom slopes as a precaution against sliding.

All traps had a circular opening of $30 \mathrm{~cm}$ diameter. Traps of the first type, bottom traps, resembled conical plankton nets or classic seston traps with walls made of impermeable fabrics and the nylon net. They were 
Table 1 Morphometric data and location of the studied lakes

\begin{tabular}{|c|c|c|c|c|c|c|}
\hline & \multirow[t]{2}{*}{ Lake name } & \multirow[t]{2}{*}{ Maximum depth (m) } & \multirow[t]{2}{*}{ Mean depth (m) } & \multirow[t]{2}{*}{ Area (ha) } & \multicolumn{2}{|c|}{ Location (DD) } \\
\hline & & & & & Latitude (N) & Longitude (E) \\
\hline \multirow[t]{5}{*}{ Shallow lowland } & Długie & 12.1 & 4.6 & 30 & 54.06006 & 22.31284 \\
\hline & Jorzec & 11.6 & 5.5 & 42 & 53.83568 & 21.51471 \\
\hline & Kociołek & 13.3 & 6.5 & 15 & 54.05053 & 22.33204 \\
\hline & Sołtmany & 12.5 & 5.5 & 180 & 54.04589 & 22.01903 \\
\hline & Wojnowo & 14.2 & 6.3 & 18 & 53.95043 & 21.85509 \\
\hline \multirow[t]{3}{*}{ Deep lowland } & Hańcza & 108.5 & 38.7 & 311 & 54.27614 & 22.81725 \\
\hline & Okmin & 39.9 & 13.0 & 114 & 54.15403 & 22.83121 \\
\hline & Ożewo & 55.5 & 18.3 & 55 & 54.14799 & 22.80869 \\
\hline Deep mountain & Czarny Staw & 76.4 & 37,6 & 21 & 49.18841 & 20.07522 \\
\hline
\end{tabular}

set up vertically in the hypolimnion, at the depth of $11 \pm 1 \mathrm{~m}$ in shallow and $25 \pm 1 \mathrm{~m}$ in deep lakes. The opening of the trap was situated 2-3 m above the bottom in order to reduce possible contamination with ephippia accumulated in bottom sediments that could be stirred up by fish or water circulation. The top of each conical trap was attached to a buoy, while the bottom was held by an anchor to keep the trap at the required depth. An additional line linking the buoy with the wide opening of the net was used to close the trap when it was moved up or down during sampling. A 12-cm long and 7-cm wide cylindrical removable glass container was attached to the bottom of the conical net, which accumulated sinking seston

Fig. 2 Outline of the trap design

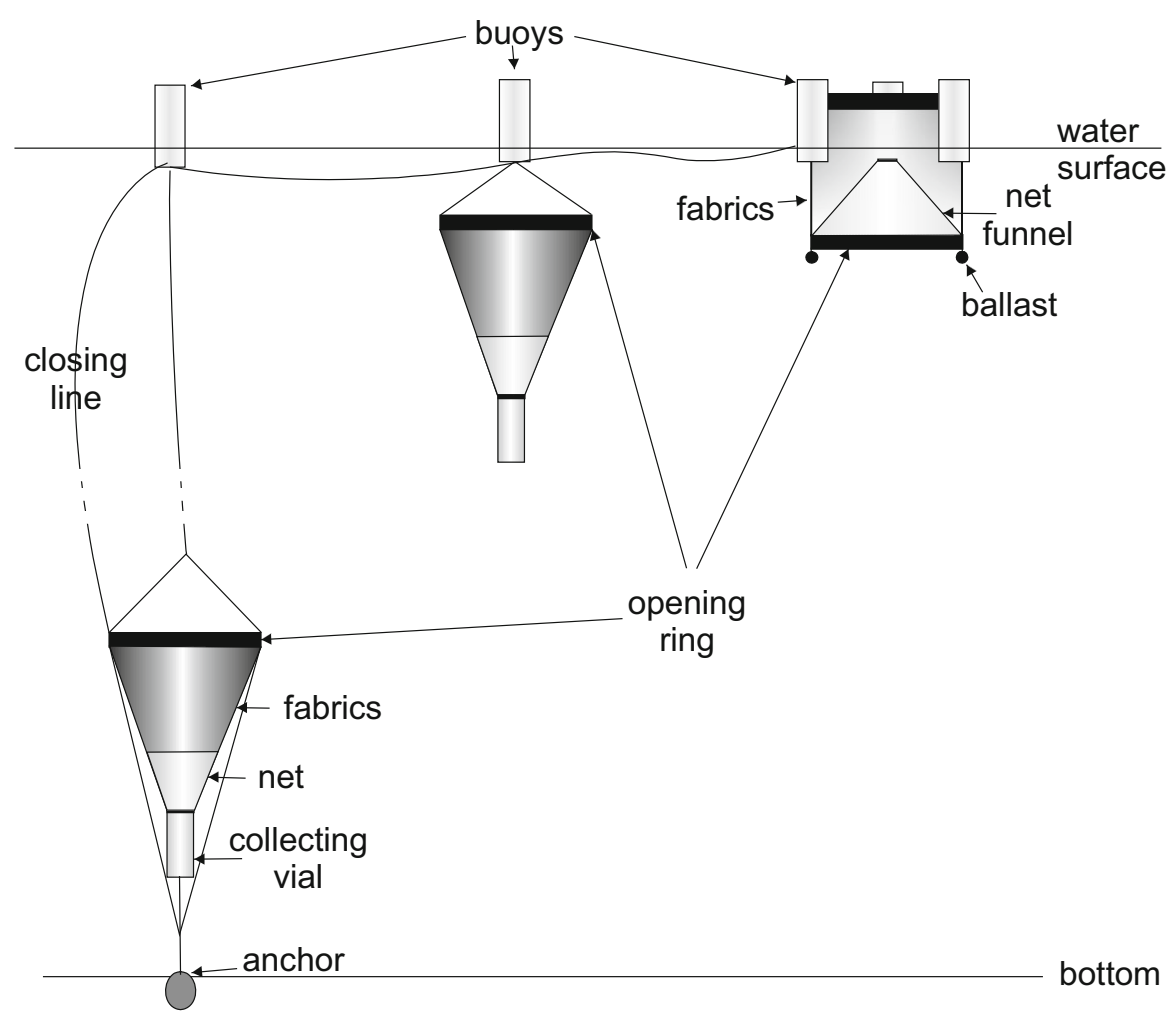


particles falling into the trap. These traps were designed to quantitatively collect ephippia sinking to the bottom of the lake. The same traps were successfully used all year round in our former studies to determine timing and quantities of ephippia production in the studied lakes (Grabowski, 2006; Surga, 2007). Similar traps were recently described and used by Brandão et al. (2014). Ephippia collected in these traps could be of two different origins. These were (1) the ephippia that directly sank to the bottom after being released by female in the water column, or (2) ephippia that floated initially but got detached from the surface and sank during the study period.

Traps of the second type, subsurface traps, resembled the traps of the first type, except they were positioned $20 \mathrm{~cm}$ below the water surface. They were not anchored but suspended under a buoy which was attached by a line to the buoy of the former trap. Heavy glass containers at their bottoms maintained them in the upright and submerged position. These traps were designed to collect only the ephippia that floated initially but got detached from the surface and sank during the experiment. Although they would also collect ephippia shed by females just under the water surface, we find this scenario marginal, however. The traps of these first two types allowed estimating the production of sinking ephippia and discriminating between those that sank directly and those that temporarily floated before sinking.

Traps of the third type, surface traps, consisted of a cylindrical wall made of impermeable fabrics with an inverted funnel opening made of a nylon net (similar as in plankton nets) at its bottom end. These traps had the standard $30-\mathrm{cm}$ wide opening at the bottom and a 4-cm wide circular opening at the top of the inverted funnel placed $5 \mathrm{~cm}$ below the water surface (Fig. 2). The surface traps were floating at the water surface thanks to three buoys attached outside cylindrical wall and were not anchored directly, but connected with a line to the buoy of the subsurface trap. Small ballasts attached to the bottom ring of the surface traps kept them in upright position. These traps could move up and down with waves, maintaining their shape and position relative to the surface. Ephippia or ephippial females that reached the surface through the trap opening had little chance of sinking to the bottom. Even if they got detached from the surface subsequently, they stayed trapped within. These traps were designed to quantify the total production of floating ephippia, irrespectively of their later fate, i.e. staying at the surface or sinking during the study.

By analysing the content of the three traps in a set, we were able to estimate the production of floating and sinking ephippia, as well as the rates of detachment of the floating ephippia from the surface and their subsequent sinking. For each estimation, we took the mean number of ephippia found in the two traps of a certain type placed in a lake. The quantity of the floating ephippia that got detached from the surface was estimated as: Efdet $=$ Nss, where Nss is the number of ephippia found in the subsurface trap. The quantity of ephippia that remained floating was estimated as Efrem $=$ Ns - Nss, where Ns is the number of ephippia found in the surface trap. The quantity of the directly sinking ephippia was calculated as Esink $=\mathrm{Nb}-\mathrm{Nss}$, where $\mathrm{Nb}$ is the number of ephippia found in the bottom trap. The total quantity of ephippia produced during the experiment was estimated as the sum of the three above: Etotal $=$ Efdet + Efrem + Esink $=\mathrm{Ns}+\mathrm{Nb}-\mathrm{Nss}$. The samples were recovered and retained in a dark refrigerator until quantitative estimation of ephippial shells under a dissecting microscope, which was done within 4 weeks of collection. Initial test performed with the bottom traps revealed that only in the time of ephippia production some ephippia got caught in the traps (Grabowski, 2006).

Lab verification of floating ephippia production

In order to verify the efficiency of the seston traps in determining the proportion of ephippia reaching the water surface, we performed laboratory test similar to the procedure described in our previous study (Ślusarczyk \& Pietrzak, 2008). Large vertical zooplankton samples were collected with a plankton net in the deepest spot of one of the investigated lakes (Kociołek) on the day when the seston traps were being removed from the lake. Live animals were transferred to the lab in a substantial volume of water. Daphnia carrying dark coloured ephippia (which indicates late stage of ephippial development) were selected from the live samples and transferred to experimental vials within $6 \mathrm{~h}$ of collection. Twelve ephippial females were moved to each of ten $125 \mathrm{ml}$ cylindrical glass vials $(25 \mathrm{~cm}$ high, $2.5 \mathrm{~cm}$ in diameter) filled with 
water from the native lake $(12 \times 10=120$ females $)$. The lake water was supplemented with the green algae Scenedesmus obliquus at a concentration of $0.3 \mathrm{mg} \mathrm{C}$ $1^{-1}$ as food for the Daphnia. The experimental vials were exposed from top to constant UV radiation (generated by a $40 \mathrm{~W}$ Phillips Cleo UV fluorescent tanning bulb), of approximate intensity $2.5 \mu \mathrm{mol} \mathrm{m} \mathrm{m}^{-2}$ $\mathrm{s}^{-1}$ at the water surface. UV light was applied to discourage the experimental females from staying close to the surface and prevent accidental shedding of ephippia at the water plane in the shallow cylindrical vials. The experiment was conducted at ambient temperature $\left(10 \pm 2^{\circ} \mathrm{C}\right)$, for $48 \mathrm{~h}$ until most females had shed their ephippia. The quantity of ephippia found at the surface (considered to be oviposited there by ephippial females) was then compared with the number of ephippia found at the bottom (considered to be ephippia released in the water column).

\section{Assessment of egg content status}

The egg content of ephippia collected with the seston traps in the studied lakes was analysed under dissecting microscope. All collected ephippia were screened for egg content. Since ephippial shells were sufficiently transparent, the egg number could be estimated without opening the ephippia. The proportion of empty ephippia, i.e. containing no eggs, was compared between different groups of ephippia. Data for egg content status were available for all except one shallow lake.

\section{Measurement of female vertical distribution}

We tested the prediction of differential non-ephippial and ephippial females vertical distribution in the deep mountain lake (Czarny Staw, $76 \mathrm{~m}$ ). It was the only lake with high $(>10 \%)$ relative abundances of ephippial females on any single sampling date. The other rationale for choosing this lake was the stable summer stratification of the water throughout the sampling period, as ephippia production begins earlier there. This minimises the influence of physical water mixing on zooplankton distribution. Fully stratified zooplankton samples were taken at the deepest spot of the lake. Vertical tows through either 5 or $10 \mathrm{~m}$ deep layers were taken at day and night with a quantitative plankton closing net of a circular opening of $28 \mathrm{~cm}$ diameter. Samples were analysed as above, within
$12 \mathrm{~h}$ from collection. Day and night distributions of ephippium-carrying and non-ephippial Daphnia females were compared. Of the two morphologically distinct lineages of Daphnia occurring in the lake, only the ephippia producing lineage was included in the analysis (those that overwinter as adults were excluded from analysis) (Ślusarczyk, 2009).

\section{Statistical analysis}

Whenever lakes of different types were compared, only lowland lakes, shallow and deep, were considered. The single deep mountain lake was excluded from these comparisons, as of different types and having no replicates. Numbers of floating ephippia produced were compared between shallow and deep lowland lakes with ANCOVA (overall ephippia production as covariate). Test assumptions being met, proportions of different types of ephippia and of eggs of different content statuses were arcsine transformed and compared using either one or two-sample t-tests (Zolman, 1993). Proportion test was used for testing the share of ephippia of different types in the mountain lake. Proportions of floating and sinking ephippia were compared between the lab and field using two-sample $t$ test on arcsine transformed data. Statistical analyses were performed in $\mathrm{R}$ (ver. 3.1.1).

\section{Results}

Quantification of floating ephippia production

The estimated numbers of floating ephippia produced during sampling, whether they sank within this period or not, were substantial and ranged from 286 to 2836 ephippia $\mathrm{m}^{-2}$ per month in lowland lakes dominated by Daphnia from the longispina group, and reached 3814 ephippia $\mathrm{m}^{-2}$ per month in the mountain lake Czarny Staw inhabited by Daphnia from the pulex group. The numbers of floating ephippia increased with overall ephippia production $\left(\right.$ per $\mathrm{m}^{2}$ ), did not differ between deep and shallow lowland lakes, yet the rate of increase was higher in the latter (ANCOVA: ephippia production: $F=44.24$, df $=1, P=0.0027$, lake depth: $F=0.21, \quad \mathrm{df}=1, \quad P=0.67$, lake depth $\times$ ephippia production: $F=10.51, \mathrm{df}=1$, $P=0.0316$, Fig. 3). 
Majority of the ephippia produced during the sampling period were initially floating, though the proportion varied greatly between lakes $(60 \pm 32 \%$, mean $\pm \mathrm{SD}$ ). The proportion of floating ephippia was not associated with the overall numbers of ephippia produced, but differed between lowland shallow and deep lakes (Welch two-sample $t$ test: $t=7.36$, $\mathrm{df}=4.5, P=0.0011$ ), and equalled $81 \pm 12$ and $21 \pm 4 \%$, respectively (Fig. 4). There were more floating than directly sinking ephippia in shallow lakes (one sample t-test (null hypothesis of equal proportion): $t=4.67$, df $=4, P=0.0095$ ), and in the deep mountain lake $(78 \%$, proportion test: $Z=39.34$, $P<0.0001)$. On the contrary, in deep lowland lakes, sharing gross taxonomic composition of Daphnia community with the shallow lowland lakes, and morphology with the mountain lake, most ephippia sank directly to the bottom $(t=11.6, \quad \mathrm{df}=2$, $P=0.0074)$.

About half of the initially floating ephippia got detached and sank during the sampling period $(55 \pm 30 \%$, one sample $t$ test: $t=1.02$, df $=8$, $P=0.34$ ). This fraction did not differ significantly between the shallow and deep lowland lakes (twosample $t$ test: $t=0.89$, df $=2.8, P=0.46$ ), and was similar in the deep mountain lake $(46 \%)$. Overall, $31 \pm 26 \%$ of ephippia produced in the studied lakes remained at the water surface, and $69 \pm 26 \%$ sank to the bottom eventually, but only in deep lowland lakes $(92 \pm 8 \%)$ this was a significant majority of the

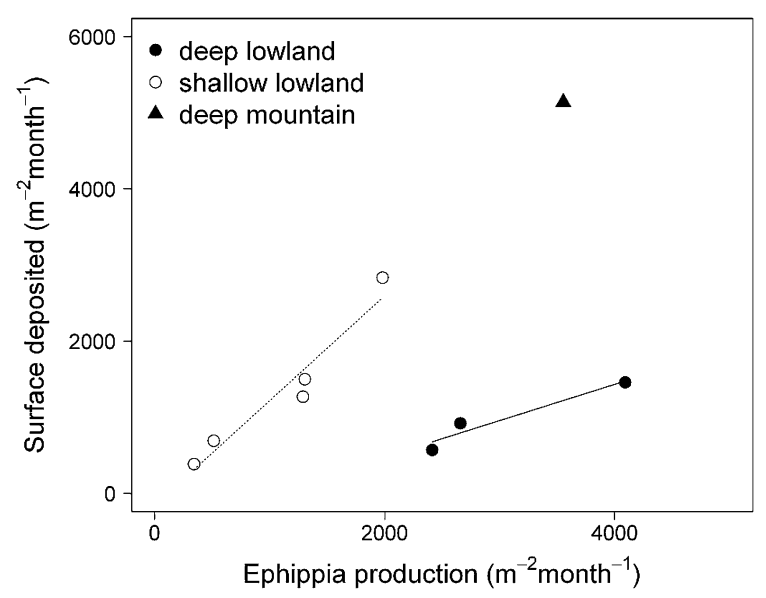

Fig. 3 Estimated densities of floating ephippia versus overall densities of ephippia accumulated during a month of ephippia formation period ephippia (one sample $t$ test: $t=4.70, \quad \mathrm{df}=2$, $P=0.0424)$.

Lab verification of floating ephippia production

The laboratory test on ephippial Daphnia derived from the shallow lake Kociołek revealed that $89 \pm 7 \%$ (mean $\pm \mathrm{SD}$ ) of ephippia of Daphnia of the longispina group were found floating at the water surface, which is not significantly different from the estimated value in the field $(95 \pm 8 \%$ ) (Welch two-sample $t$ test: $t=-1.34$, df $=9.99, P=0.21)$.

Egg content status

Of all 3280 Daphnia ephippia checked for egg content status, $11 \pm 3 \%$ (mean $\pm \mathrm{SD}$ ) were empty. Proportion of empty ephippia did not differ between floating and directly sinking ephippia ( $20 \pm 18$ vs. $21 \pm 21 \%$, respectively, paired $t$ test: $t=0.09, \quad \mathrm{df}=7$, $P=0.93)$, nor it differed between shallow and deep lowland lakes $(24 \pm 2$ vs. $22 \pm 2 \%$, two-sample $t$ test: $t=0.26$, df $=11.2, P=0.8$ ) (Fig. 5). Among the floating ephippia, the proportion of empty ephippia was lower in the detached ephippia than in those that remained at the surface ( $6 \pm 6$ vs. $47 \pm 43 \%$, respectively, paired $t$ test: $t=-2.52$, df $=7, P=0.04)$. Yet, this did not translate into significant difference in the proportion of empty ephippia between those that remained at the surface and those that reached the bottom during sampling period $(47 \pm 43$ vs. $13 \pm 12 \%$, respectively, paired $t$ test: $t=2.07$, $\mathrm{df}=7, P=0.078)$.

Female vertical distribution

During the period of ephippia production in Czarny Staw, individuals carrying ephippium stayed in the top $5 \mathrm{~m}$ layer at night more frequently than individuals without ephippium (over $65 \%$ compared to $25 \%$, $\chi^{2}>22.6, P=0.001$; Fig. 6). At night, Daphnia carrying ephippium stayed on average closer to the surface than those with subitaneous or no eggs (median 2.5 vs. $12.5 \mathrm{~m}$, respectively), and both groups avoided surface layers and stayed deeper in the water column during the day (both medians $25 \mathrm{~m}$ ) despite the absence of fish. All vertical distributions were significantly different from each other $\left(\chi^{2}>35.5\right.$, $P<0.0001)$. 
Fig. 4 Proportion of ephippia sinking directly to the bottom, floating initially on the surface but detached later, and remaining floating at the end of sampling period. From D to Oo: lowland lakes dominated by D. cucullata, among them D-W: shallow lowland lakes, H-Oo: deep lowland lakes; CS: deep mountain lake dominated by $D$. pulicaria

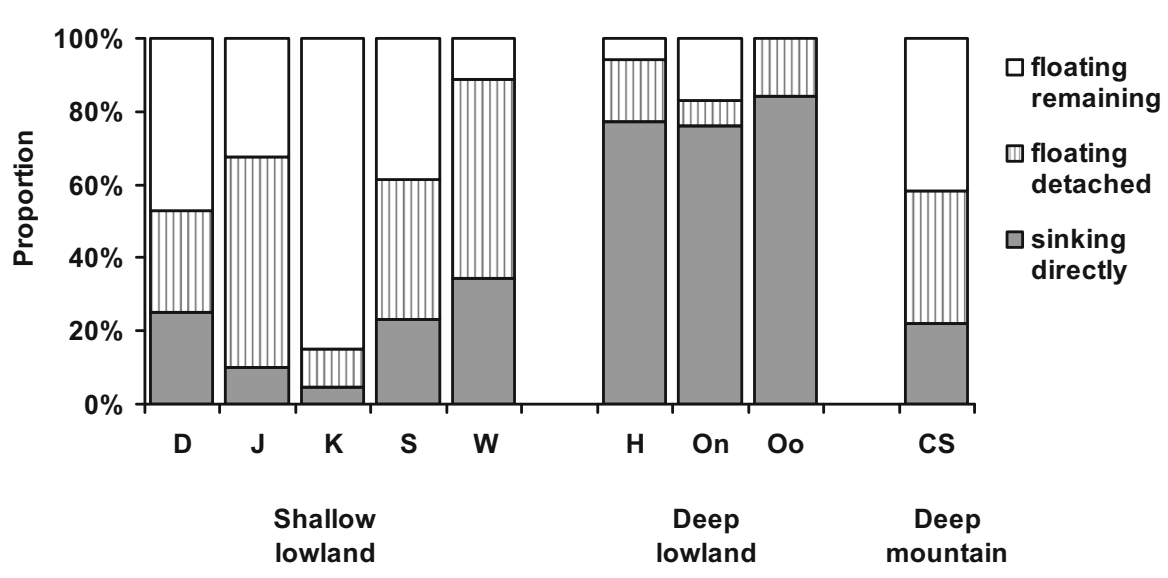

We expect the massive floating of ephippia, as documented by this study, to play an important role in Daphnia dispersal. Most lakes are temporal habitats in geological and evolutionary timescales, and organisms inhabiting them need effective mechanisms of between-lake dispersal, otherwise they would go extinct. Numerous studies show that effective passive transport of freshwater plankters between water bodies, followed by successful colonisation, is likely rare (Shurin, 2000; Bohonak \& Jenkins, 2003), due to strong isolation between the suitable habitats on the one hand, and founder effects therein on the other (Shurin, 2000; Louette \& DeMeester, 2005; De Meester et al., 2002; Havel \& Shurin, 2004). Yet, their high dispersal potential is clearly seen in their rapid invasion of new habitats (Louette \& De Meester, 2005) and vast distribution of some genotypes (Taylor et al., 1998; Weider et al., 1999a, b). Indeed, it has been shown that under high dispersal rates mass effects can overcome species sorting (Souffreau et al., 2014). And to maintain any reasonable rate of dispersal, traits that facilitate dispersal are needed, and many organisms display features that appear to increase its likelihood (Bilton et al., 2001). In very shallow waters, ephippia irrespective of their sinking or floating may easily get in contact with dispersal vectors, and thanks to adherent properties get attached and effectively moved. Cladoceran ephippia from rock pools and wetlands get dispersed through overflows (Vanschoenwinkel et al., 2008a), by wind (Cáceres \& Soluk, 2002; Vanschoenwinkel et al., 2009), and by birds and mammals, including humans (Vanschoenwinkel et al., 2008b; Waterkeyn et al., 2010; Simonis \& Ellis, 2014). In lakes, it is floating that may greatly 
Fig. 6 Vertical distribution of Daphnia pulicaria in the deep mountain lake, Czarny Staw, during the period of ephippia production: at night (grey panels) and during the day (white panels)

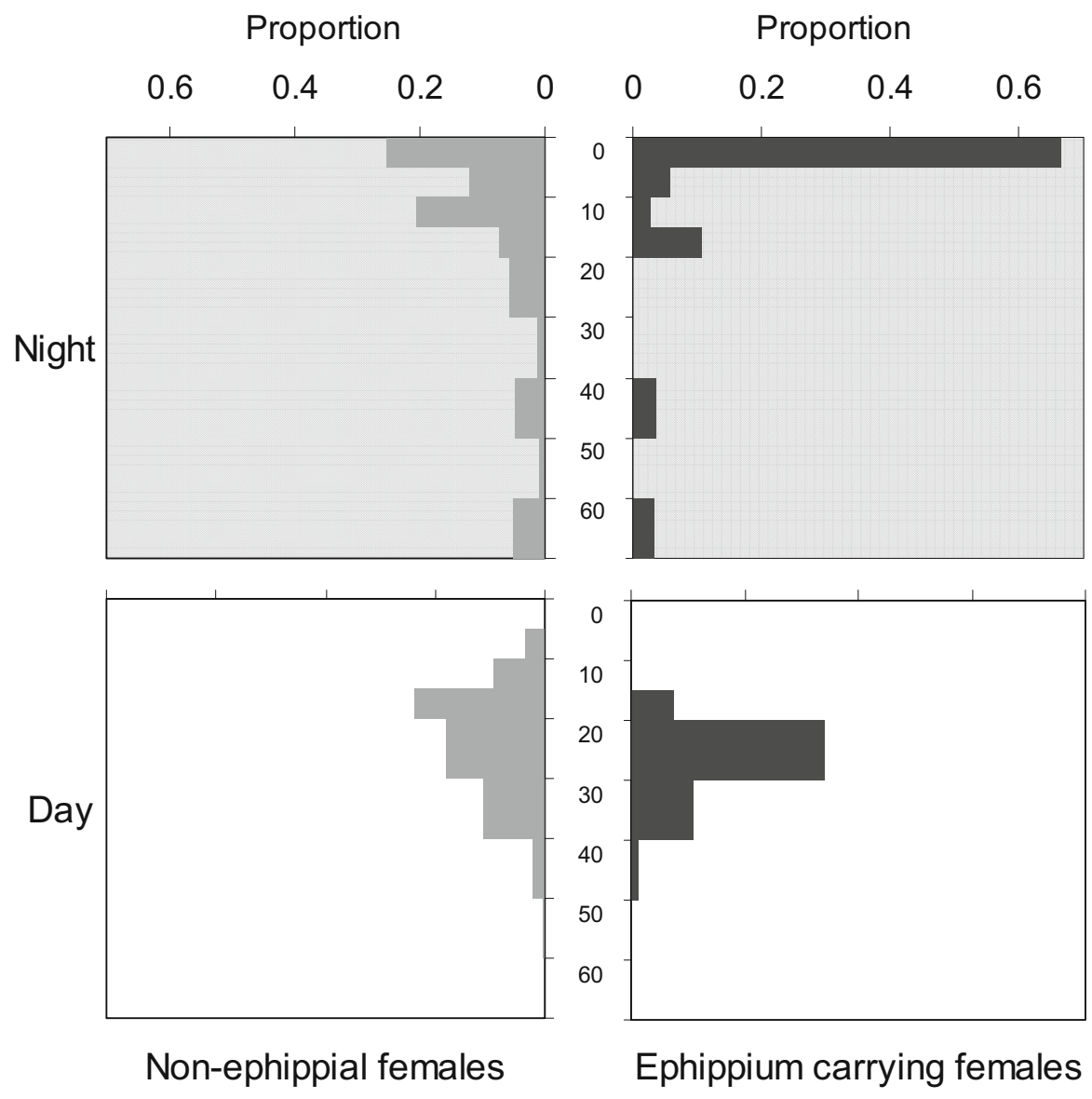

increase the chances of ephippia contact with dispersing vectors.

Ephippia float in great numbers despite their initial negative buoyancy. The results of our previous studies (Ślusarczyk \& Pietrzak, 2008; and unpublished data) showed that not a single of the several hundreds of ephippia that were examined had positive buoyancy before contact with atmospheric air (Cáceres et al., 2007 also dealt with ephippia buoyancy, yet their method did not ensure lack of contact of the ephippia with the air during the experiment). Ephippia are thus brought to the surface by external forces, such as their mothers, water movements, adhered air bubbles, or combination thereof. While we did not test in a direct way how ephippia appeared at the water surface in the field, our laboratory observations (Ślusarczyk \& Pietrzak, 2008; and this study) indicate that this is due to females that swim upward and stick ephippia to the water surface during moulting. Our lab observations of the surface oviposition behaviour of the females are further supported by the vertical distribution of ephippiumcarrying females (Fig. 6), i.e. a strong bias towards staying close to the surface in comparison to that of nonephippial females at night, when environmental surface threats (UV radiation or fish predation in lakes inhabited by fish) are low. This diurnal rhythm of ephippia oviposition at the water surface and wind action which sweeps out floating ephippia toward the shore may lead to diurnal fluctuations in ephippia density at the water surface in offshore part of the lakes with highest values at dawn and lowest at dusk (unpublished data). Whether vertical distribution of the females is indicative of selective pressures acting on developmental time (higher temperature, see Pietrzak et al., 2013), or on dispersal, the result is a massive surface deposition of ephippia.

The ultimate reasons for the observed differences in proportions of floating ephippia between tested lakes remain unclear. These differences may arise from different oviposition behaviours of Daphnia, driven 
by different environmental conditions on one hand, and different species compositions in these lakes on the other. While in shallow eutrophic lowland lakes $D$. cucullata was the dominating Daphnia species, in deep mesotrophic lowland lakes it coexisted with $D$. longispina (personal observation). The ultraoligotrophic mountain lake is inhabited by Daphnia pulicaria. Irrespective of species composition, it could be proposed that higher proportion of floating ephippia in shallow lowland lakes may be a result of higher selective pressure for mechanisms of effective spatial dispersal in more variable and less predictably changing habitats. Yet, the very high proportion of floating ephippia in the deep mountain lake calls for another explanation.

Some of the collected ephippia appeared empty (11\% approximately). Either eggs were never deposited in those ephippia, or decayed or hatched before being scored. The decision of ephippium formation precedes resting eggs deposition in ephippial case (Hiruta \& Tochinai, 2014). The ephippial eggs, which in most Daphnia are formed in meiotic way, if not fertilised, may be resorbed or decompose with time. This is not the case of parthenogenetically produced ephippial eggs, which do not need fertilisation to develop. Indeed, we found the lowest share of empty ephippia in the deep mountain lake, where the local Daphnia are obligate parthenogens, and the ephippia are thus produced asexually (Markova et al., 2007; Ślusarczyk, 2009). The share of empty ephippia was higher in lowland lakes inhabited by sexual populations, still it was equal among those first floating and those directly sinking. This shows that floating ephippia are important temporal egg bank and not just a collection of leftover or damaged shells, as is sometimes assumed.

\section{Conclusions}

The results of this study revealed numbers of ephippia floating at lakes surface reaching thousands per square metre at the time of ephippia production, and constituting significant share of that production. The results also indicate that these ephippia are brought to the surface by females, which stays in line with earlier laboratory observations. Irrespective of the way they get to the surface, part of the initially floating ephippia sinks within few weeks. An effective dispersal mechanism emerges: some of negatively buoyant ephippia are brought by females to the surface, and after a floating period-time of exposure to surface dispersal vectors - they sink into the sediments, either in the original lake or possibly after having been dispersed to another lake. All this calls for a wider recognition of the temporal surface bank of ephippia, both by plankton ecologists and by broader public. There might be need for more cautious behaviours, since the magnitude of the phenomenon is significant and human actions involuntarily increase dispersal likelihood (see e.g. Anderson et al., 2014), unwanted invasive species like D. lumholtzi included.

Acknowledgements The study was supported by grant money from Polish Ministry of Science and Higher Education (2P 04F069 27) and by National Science Centre Poland (2012/05/B/ NZ8/01232). We thank Piotr Bernatowicz for sharing an image of ephippial Daphnia and Maciej Rojek for field assistance in a mountain lake. Adam Petrusek and two anonymous reviewers provided valuable comments which helped improve the manuscript.

Open Access This article is distributed under the terms of the Creative Commons Attribution 4.0 International License (http:// creativecommons.org/licenses/by/4.0/), which permits unrestricted use, distribution, and reproduction in any medium, provided you give appropriate credit to the original author(s) and the source, provide a link to the Creative Commons license, and indicate if changes were made.

\section{References}

Altermatt, F. \& D. Ebert, 2008. The influence of pool volume and summer desiccation on the production of the resting and dispersal stage in a Daphnia metapopulation. Oecologia 157: 441-452.

Anderson, L. G., P. C. L. White, P. D. Stebbing, G. D. Stentiford \& A. M. Dunn, 2014. Biosecurity and vector behaviour: Evaluating the potential threat posed by anglers and canoeists as pathways for the spread of invasive non-native species and pathogens. PLoS ONE 9: e92788.

Baskin, C. C. \& J. M. Baskin, 2001. Seeds: Ecology, Biogeography, and Evolution of Dormancy and Germination. Academic Press, San Diego.

Bilton, D. T., J. R. Freeland \& B. Okamura, 2001. Dispersal in freshwater invertebrates. Annual Review of Ecology and Systematics 32: 159-181.

Bohonak, A. J. \& D. G. Jenkins, 2003. Ecological and evolutionary significance of dispersal by freshwater invertebrates. Ecology Letters 6: 783-796.

Brandão, L. P., D. G. Pujoni \& P. M. Maia-Barbosa, 2014. Seasonal dynamics of Daphnia laevis Birge, 1878 ephippia in a tropical lake with a description of a new methodology 
for in situ evaluation. Brazilian Journal of Biology 74: 642-648.

Cáceres, C. E. \& D. A. Soluk, 2002. Blowing in the wind: a field test of overland dispersal and colonization by aquatic invertebrates. Oecologia 131: 402-408.

Cáceres, C. E., A. N. Christoff \& W. J. Boeing, 2007. Variation in ephippial buoyancy in Daphnia pulicaria. Freshwater Biology 52: 313-318.

Clobert, J., E. Danchin, A. A. Dhondt \& J. D. Nichols (eds), 2001. Dispersal. Oxford University Press, New York.

Cote, J., S. Fogarty, B. Tymen, A. Sih \& T. Brodin, 2013. Personality-dependent dispersal cancelled under predation risk. Proceedings of the Royal Society B Biological Sciences 280: 20132349.

De Meester, L., A. Gómez, B. Okamura \& K. Schwenk, 2002. The Monopolization Hypothesis and the dispersal-gene flow paradox in aquatic organisms. Acta Oecologica 23: 121-135.

Du, N. S. \& Y. P. Li, 1990. Ultrastructural studies on the ephippium of Daphnia (Ctenodaphnia) carinata (Crustacea: Cladocera). Acta Zoologica Sinica 36: 341-344.

Figuerola, J. \& A. J. Green, 2002. Dispersal of aquatic organisms by waterbirds: a review of past research and priorities for future studies. Freshwater Biology 47: 483-494.

Figuerola, J., A. J. Green \& T. C. Michot, 2005. Invertebrate eggs can fly: evidence of waterfowl-mediated gene flow in aquatic invertebrates. American Naturalist 165: 274-280.

Grabowski, T., 2006. Utilisation of seston traps for dormant period assessment of planktonic cladocerans of the genus Daphnia. BA thesis, University of Warsaw.

Havel, J. E. \& J. B. Shurin, 2004. Mechanisms, effects, and scales of dispersal in freshwater zooplankton. Limnology and Oceanography 49: 1229-1238.

Havel, J. E., J. K. Colbourne \& P. D. N. Hebert, 2000. Reconstructing the history of intercontinental dispersal in Daphnia lumholtzi by use of genetic markers. Limnology and Oceanography 45: 1414-1419.

Hiruta, C. \& S. Tochinai, 2014. Formation and structure of the ephippium (resting egg case) in relation to molting and egg laying in the water flea Daphnia pulex De Geer (Cladocera: Daphnidae). Journal of Morphology 275: 760-767.

Hopfensperger, K. N. \& A. H. Baldwin, 2009. Spatial and temporal dynamics of floating and drift-line seeds at a tidal freshwater marsh on the Potomac River, USA. Plant Ecology 201: 677-686.

Jankowski, T. \& D. Straile, 2003. A comparison of egg-bank and long-term plankton dynamics of two Daphnia species, $D$. hyalina and D. galeata: Potentials and limits of reconstruction. Limnology and Oceanography 48: 1948-1955.

Juračka, P. J., V. Kořinek \& A. Petrusek, 2010. A new Central European species of the Daphnia curvirostris complex. Zootaxa 2718: 1-22. (Daphnia hrbaceki sp. nov. (Cladocera, Anomopoda, Daphniidae)).

Kappes, H., O. Tackenberg \& P. Haase, 2014. Differences in dispersal- and colonization-related traits between taxa from the freshwater and the terrestrial realm. Aquatic Ecology 48: 73-83.

Karlson, R. H., 1992. Divergent dispersal strategies in the freshwater bryozoan Plumatella repens: ramet size effects on statoblast numbers. Oecologia 89: 407-411.
Kerfoot, W. C., J. W. Budd, B. J. Eadie, H. A. Vanderploeg \& M. Agy, 2004. Winter storms: sequential sediment traps record Daphnia ephippial production, resuspension, and sediment interactions. Limnology and Oceanography 49: 1365-1381.

Van Leeuwen, C. H. A., J. M. Sarneel, J. van Paassen, W. J. Rip \& E. S. Bakker, 2014. Hydrology, shore morphology and species traits affect seed dispersal, germination and community assembly in shoreline plant communities. Journal of Ecology 102: 998-1007.

Levin, S. A., D. Cohen \& A. Hastings, 1984. Dispersal strategies in patchy environments. Theoretical Population Biology 26: 165-191.

Louette, G. \& L. De Meester, 2005. High dispersal capacity of cladoceran zooplankton in newly founded communities. Ecology 86: 353-359.

Maguire Jr, B., 1963. The passive dispersal of small aquatic organisms and their colonization of isolated bodies of water. Ecological Monographs 33: 161-185.

Markova, S., F. Dufresne, D. J. Rees, M. Černý \& P. Kotlík, 2007. Cryptic intercontinental colonization in water fleas Daphnia pulicaria inferred from phylogenetic analysis of mitochondrial DNA variation. Molecular Phylogenetics and Evolution 44: 42-52.

Panov, V. E. \& C. Cáceres, 2007. Role of Diapause in Dispersal of Aquatic Inverteb rates. In Alekseev, V. R., B. T. De Stasio \& J. J. Gilbert (eds), Diapause in Aquatic Invertebrates, Theory and Human Use. Springer, Dordrecht: 187-195.

Panov, V. E., P. I. Krylov \& N. Riccardi, 2004. Role of diapause in dispersal and invasion success by aquatic invertebrates. Journal of Limnology 63: 56-69.

Pietrzak, B. \& M. Ślusarczyk, 2006. The fate of the ephippiaDaphnia dispersal in time and space. Polish Journal of Ecology 54: 709-714.

Pietrzak, B., A. Bednarska, M. Markowska, M. Rojek, E. Szymanska \& M. Slusarczyk, 2013. Behavioural and physiological mechanisms behind extreme longevity in Daphnia. Hydrobiologia 715: 125-134.

Pinceel, T., B. Vanschoenwinkel \& L. Brendonck, 2013. Flexible dispersal dimorphism in zooplankton resting eggs: an example of repeated phenotypic coin flipping? Biological Journal of the Linnean Society 110: 749-756.

Pollux, B. J. A., E. Verbruggen, J. M. Van Groenendael \& N. J. Ouborg, 2009. Intraspecific variation of seed floating ability in Sparganium emersum suggests a bimodal dispersal strategy. Aquatic Botany 90: 199-203.

Radzikowski, J., 2013. Resistance of dormant stages of planktonic invertebrates to adverse environmental conditions. Journal of Plankton Research 35: 707-723.

Schultz, T. W., 1977. Fine structure of the Ephippium of Daphnia pulex (Crustacea: Cladocera). Transactions of the American Microscopical Society 96: 313-321.

Shurin, J. B., 2000. Dispersal limitation, invasion resistance, and the structure of pond zooplankton communities. Ecology 81: 3074-3086.

Silvertown, J. \& D. Charlesworth, 2001. Introduction to Plant Population Biology, 4th ed. Iowa State University Press, Iowa.

Simonis, J. L. \& J. C. Ellis, 2014. Bathing birds bias $\beta$-diversity: frequent dispersal by gulls homogenizes fauna in a rockpool metacommunity. Ecology 95: 1545-1555. 
Souffreau, C., B. Pecceu, C. Denis, K. Rummens \& L. De Meester, 2014. An experimental analysis of species sorting and mass effects in freshwater bacterioplankton. Freshwater Biology 59: 2081-2095.

Surga, K., 2007. Production of Resting Eggs of Daphnia cucullata in the Lakes of North-East Poland. University of Warsaw, MSc.

Ślusarczyk, M., 2009. Extended lifespan traded for diapause in Daphnia. Freshwater Biology 54: 2252-2262.

Ślusarczyk, M. \& B. Pietrzak, 2008. To sink or float: the fate of dormant offspring is determined by maternal behaviour in Daphnia. Freshwater Biology 53: 569-576.

Taylor, D. J., T. L. Finston \& P. D. N. Hebert, 1998. Biogeography of a widespread freshwater crustacean: pseudocongruence and cryptic endemism in the North American Daphnia laevis complex. Evolution 52: 1648-1670.

Vanschoenwinkel, B., S. Gielen, H. Vandewaerde, M. Seaman \& L. Brendonck, 2008a. Relative importance of different dispersal vectors for small aquatic invertebrates in a rock pool metacommunity. Ecography 31: 567-577.

Vanschoenwinkel, B., A. Waterkeyn, T. Vandecaetsbeek, O. Pineau, P. Grillas \& L. Brendonck, 2008b. Dispersal of freshwater invertebrates by large terrestrial mammals: a case study with wild boar (Sus scrofa) in Mediterranean wetlands. Freshwater Biology 53: 2264-2273.
Vanschoenwinkel, B., S. Gielen, M. Seaman \& L. Brendonck, 2009. Wind mediated dispersal of freshwater invertebrates in a rock pool metacommunity: differences in dispersal capacities and modes. Hydrobiologia 635: 363-372.

Venable, D. L. \& J. S. Brown, 1988. The selective interactions of dispersal, dormancy, and seed size as adaptations for reducing risk in variable environments. American Naturalist 131: 360-383.

Waterkeyn, A., B. Vanschoenwinkel, S. Elsen, M. Anton-Pardo, P. Grillas \& L. Brendonck, 2010. Unintentional dispersal of aquatic invertebrates via footwear and motor vehicles in a Mediterranean wetland area. Aquatic Conservation: Marine and Freshwater Ecosystems 20: 580-587.

Weider, L. J., A. Hobæk, J. K. Colbourne, T. J. Crease, F. Dufresne \& P. D. N. Hebert, 1999a. Holarctic phylogeography of an asexual species complex I. Mitochondrial DNA variation in arctic Daphnia. Evolution 53: 777-792.

Weider, L. J., A. Hobæk, P. D. N. Hebert \& T. J. Crease, 1999 b. Holarctic phylogeography of an asexual species complex II. Allozymic variation and clonal structure in Arctic Daphnia. Molecular Ecology 8: 1-13.

Zolman, J. F., 1993. Biostatistics: Experimental Design and Statistical Inference. Oxford University Press, New York. 